\title{
Seasonal impact in burn profiles in a dedicated burn unit
}

\section{Luís Mata Ribeiro*, Luís Gabriel Vieira, Juliana Martins Sousa, Ana Silva Guerra}

Department of Plastic and Reconstructive Surgery, Hospital São José (Centro Hospitalar Lisboa Central), Lisbon, Portugal

\section{A R T I C L E I N F O}

Article history:

Accepted 3 March 2019

Keywords:

Season

Burn unit

Winter

Length of hospital stay

Mortality

Portugal

\begin{abstract}
A B S T R A C T
Introduction: The number of burns in Portugal remains considerably large and therefore constitutes a major public health problem. There is a shortage of studies describing the epidemiological and clinical impact of seasonality on burn centre admissions, particularly in high income countries.

Methods: This retrospective analysis included all patients ( $>18$ years old) with acute burns admitted to a specialized Burn Center in Lisbon (Hospital São José) between 20 of September 2010 and 19 of September 2017 (7 years). Clinical data was obtained from electronic medical records. The patients were categorized into four groups, according to each season.

Results: Six hundred and sixteen (616) patients were included in this analysis, the majority being male (55.2\%). There were no significant differences between the number of patients admitted in each season nor in gender distribution. Older patients were admitted during winter. Hospitalisation time was higher for patients admitted in the winter and surface area injured was higher for those admitted during summer. Fire burns were the most common aetiology in all seasons. Work related burns and suicide attempts were more frequent in the summer. Most patients had more than one anatomical area affected $(73.9 \%)$ and winter was specifically associated with more frequent isolated lower limb burns. Winter and fire burns were associated with deeper injuries. More patients underwent surgery during winter $(80.7 \%)$ than in the remaining seasons (average $65 \%$ ) but the average number of surgeries per season did not change significantly. The overall mortality rate was $6.8 \%$ and the need for mechanical ventilation was $28.9 \%$. Concerning both variables we did not find major differences across seasons. Mortality was associated with older patients, deeper and more extensive burns and need for mechanical ventilation.

Conclusion: Winter seems to be associated with older patients and with the most severe burns (deeper and more often needing surgery). This study was designed to fill the gap in seasonal burn profile in Portugal and it helps in establishing preventive strategies and better resource allocation.
\end{abstract}

○ 2019 Elsevier Ltd and ISBI. All rights reserved.

Abbreviations: LOS, length of stay; TBSA, total body surface area burned; SD, standard deviation; IR, interquartile range; H\&N, head and neck; UL, upper limb; LL, lower limb; TP, trunk and pelvis.

* Corresponding author at: Hospital São José, Plastic and Reconstructive Surgery Division, Rua José António Serrano, 1150-199, Lisboa, Portugal.

E-mail address: Luis1989ribeiro@gmail.com (L. Mata Ribeiro).

https://doi.org/10.1016/j.burns.2019.03.008

0305-4179/@ 2019 Elsevier Ltd and ISBI. All rights reserved. 


\section{Introduction}

Burns are one of the most debilitating injuries with significant impact on the quality of life of burn patients [1,2]. Besides the serious public health problem, burns are a major economic burden as the associated costs with the treatment, long hospitalisation and rehabilitation are very high [1-4].

Preventing burns is the most difficult task yet the most effective one. Most preventive measures focus on active education programs and jurisdiction enforcing the reduction of tap water temperatures, improvement of clothing standards, obligatory requirement of smoke alarms on residential housing and restricting smoking on indoor public spaces [5-8]. Despite this, no prevention campaign or imposed regulation has systematically targeted specific seasonal differences.

Although there are several reports concerning the impact of temporal factors and weather changes on trauma admissions there is still very little information regarding the potential effect of seasonal change on burn injuries and patient admissions at Burn Units [9].

The number and pattern of burns differ significantly worldwide as the prevalence of etiological factors vary in different countries and climates $[5,10]$. Several studies report a higher occurrence of burn injuries during winter [11], most of them coming from developing nations [9]. Additionally, fires are more common during winter in countries with cold climates $[4,12]$. This seems to be associated with higher electricity consumption and the use of various heating sources such as fireplaces, electric heaters and gas heating [4,11]. On the opposite, during summer the increase in temperatures and the drought of the soils contributes to the occurrence of many wildfires which can potentially cause multiple burn victims. The increased setting up of campfires and the use of bonfires and fireworks during cultural/religious festivities can also increase the number of admissions to Burn Units during this period [13,14].

Portugal has five specialized Burn Units (Lisbon (2), Coimbra, Oporto, Gaia). There are several articles published [1,15-19] describing the main epidemiologic characteristics of burn patients admitted at these facilities but as far as we know no study has focused on comparing these injuries across different seasons. The main goal of this study is to analyse the impact of seasonal change on burn patterns and patients admitted to a specialized Burn Unit. A secondary objective is to obtain epidemiological data regarding the burn profiles and suggest potential preventive measures and better resource allocation as well as highlighting specific subgroups of population at a higher risk of burn injury.

\section{Material and methods}

We performed a retrospective data analysis of all patients admitted to Hospital S. José Burn Unit during the period between 20 of September 2010 and 19 of September 2017. This Burn Unit only accepts adult patients, has 8 beds and is one of 5 specialized Burn Centres in Portugal.

From this analysis were excluded all patients admitted suffering from other injuries not associated with burns, namely patients with Stevens Johnson syndrome and necrotising fasciitis. A total of 616 patients met the conditions for inclusion.

Data was extracted from electronic medical records and included age, gender, date of admission (and season), length of stay (LOS - in days), aetiology (Fire, Hot Liquids, Electrical, Flash Burn, Contact, Chemical, Abrasion/Friction; Unknown), circumstance of burn (Personal accident, Work-related, Suicide attempt, Assault, Unknown) Total Body Surface Area burn (TBSA - \%), depth of Burn (2nd degree superficial, 2nd degree deep, 2nd degree superficial and deep, 2nd degree and 3rd degree and 3rd degree only), anatomical areas affected (Head and Neck (HN), Upper Limb (UL); Lower Limb (LL); Trunk and Pelvis (TP)), number of surgeries, need for mechanical ventilation (MV) and mortality. For purposes of statistical analysis depth of burn was then stratified in 3 groups: second degree only (superficial, deep and both), second and third degree, and third degree only. Surgeries included debridement, escharotomies, amputations, skin grafts and local/ distant flaps. All this information was then analysed according to seasonal variability (4 categories: summer between 20 June and 19 of September; autumn between 20 September and 19 of December; winter between 20 December and 20 March; spring between 21 March and 19 of June).

Data was analysed with SPSS software 24.0 (SPPS INC: 2011, Chicago, Illinois, USA). Descriptive variables were presented as means $(M)$ and standard deviations $(S D)$ for quantitative symmetrically distributed variables and medians (Mdn) and percentiles 25 and 75 (P25-P75) for quantitative non-symmetrically distributed variables. Symmetry was assessed with asymmetry coefficient, considering $[-1 ; 1]$ and histogram observation. For categorical variables, frequencies $(n)$ and proportions (\%) were presented. Parametric and non-parametric statistics were used to compare quantitative variables (ANOVA and Kruskall-Wallis, respectively) and Chi-square test was used for categorical associations (alternatively Fisher's exact test was used). Decisions regarding the use of parametric and non-parametric statistics were based on assessing normality with Kolmogorov-Smirnov statistic, histogram observation, and variances homogeneity with Levene statistic. Multiple comparisons were computed when ANOVA or Kruskall-Wallis tests were statistically significant; Tukey and Dunn's tests respectively.

Logistic univariate regression models were computed for screening potential predictors of invasive mechanical ventilation and mortality; at this stage we used $\mathrm{p}<0.10$ as a criterion for entering multivariate regression models. Logistic multivariate regression models were computed entering each potential predictor and considering $\mathrm{p}<0.05$ for statistical significance. We used Hosmer-Lemeshow test for assessing goodness of fit, considering $\mathrm{p}>0.05$ for good adjustment.

In order to model the LOS, this variable was considered as a day count. The histogram showed a very skewed distribution, with a high concentration of low counts, confirming an important assumption for using Poisson models, along with low mean and mean proximity to variance. Relative risk (RR) was used to measure the effect of each predictor on the response variable (LOS); 95\% confidence intervals and p-value (based of WALD statistic) were also presented. First, each predictor was assessed considering its univariate effect on LOS. After, a multivariate model was build entering each significant 
univariate predictor $(p<0.05)$. Variable selection for final model was based on the highest $p$-value at each step, considering exclusion to start on $\mathrm{p}>0.10$. In each final model proposal, the previously excluded variables were entered and reassessed to verify change of contribution for adjustment. The comparison of final model with the null model was assessed with the Omnibus test, having obtained $\mathrm{p}<0.05$, which indicates good adjustment. The comparison of final model with the saturated model was assessed with the deviance statistic, obtaining $p>0.05$ what indicates that the final model is not significantly different of the saturated model, a good adjustment indicator. Finally, we assessed adjustment by observing the scatterplots for predicted values vs deviance residuals and the predicted values vs observations order.

\section{Results}

\subsection{Demographics}

A total of 616 patients with serious burns admitted to Hospital São José Burn Unit between September 2010 and September 2017 were included in the study. There were no significant differences between the number of patients admitted in each season, ranging from 150 (24.4\%) patients during winter to 162 $(26.3 \%)$ patients during summer $(\mathrm{p}=0.9) .340$ patients were male (55.2\%) and 276 were female (44.8\%). There was no statistically significant difference in gender distribution amongst different seasons $(p=0.084)$ (Table 1$)$. Despite this, during winter there were more females admitted than men (80 vs 70, respectively).

Age ranged from 18 to 96 . Significant seasonal variation was found in the mean age distribution of patients $(p=0.004)$. The age of patients admitted was higher, on average, during winter $(\mathrm{M}=59.09 ; \mathrm{SD}=21.54)$ and lower on summer $(\mathrm{M}=51.12 ; \mathrm{SD}=$ 19.10) (Table 1). At admission, females were significantly older than males (61.2 years vs 49.1 years, $\mathrm{p}<0.001)$.

\subsection{Length of stay (LOS)}

The mean and median LOS was 27.7 and 20 days respectively (Table 1), with a range of 1-253 days. There were statistically significant differences between seasons. Median LOS was shorter for patients admitted during autumn (18 days) and longer for those admitted during winter (22 days) $(p=0.036)$.

Results for the univariate poisson models (Table 2) showed that males are more likely to be hospitalized for longer periods $(R R=1.08 ; p<0.001)$ and work-related burn patients are less prone to longer LOS compared with personal accidents $(R R=0.93$; $\mathrm{p}<0.001$ ). Regarding aetiology, considering hot liquids as a reference category, fire burns $(R R=1.45 ; p<0.001)$, electrical burns $(R R=1.19 ; p<0.001)$ and chemical burns $(R R=1.12$; $\mathrm{p}=0.023)$ are related with longer LOS; on the contrary flash burns $(R R=0.60 ; p<0.001)$ and contact burns $(R R=0.92 ; p<0.001)$ were related with shorter periods of hospitalization. Regarding anatomical areas, HN and UL were associated with higher LOS $(R R=25.87$ and $R R=25.21$, respectively). Total number of areas affected was also increasingly associated with longer LOS. Deeper burns were associated with longer LOS compared to exclusively 2nd degree burns. Increasing number of surgeries as well as need for MV were was also related with higher LOS. Older patients were more likely to stay longer periods in the hospital $(R R=1.01$; $\mathrm{p}<0.001$ ) as well as patients with higher TBSA.

Regarding multivariate analysis the predictors that stood were fire burns compared to hot liquids $(R R=107.15 ; p=0.019)$, older patients $(R R=1.14 ; p=0.010)$ and with higher TBSA $(\mathrm{RR}=2.12 ; \mathrm{p}<0.001)$ (Table 2).

\subsection{TBSA}

The mean and median TBSA was $13.2 \%$ and $8 \%$, respectively. TBSA ranged from $0.5 \%$ to $91 \%$. There was a statistically significant difference in the median TBSA distribution (Table 1) according to season $(\mathrm{p}<0.001)$, being higher during summer $(\mathrm{Mdn}=10)$ and lower during winter $(\mathrm{Mdn}=7)$.

\subsection{Anatomical area}

The most frequent site injured was the upper limb (affected in $73.2 \%$ of patients), followed by the TP (54.7\% of patients), LL (51.6\% of patients) and $\mathrm{HN}$ ( $48.7 \%$ of patients).

Most patients had more than one area affected (73.9\%). The total number of anatomical regions injured was higher on summer $(M d n=3.0)$, compared to spring $(M d n=2.0)(p=0.01)$ and winter $(M d n=2.0)(p<0.001)$. Considering the association between anatomical regions affected and season, results show that, overall, UL was the most frequent site injured. Significant

Table 1 - Demographics, LOS, TBSA and total number of anatomical regions affected compared by season.

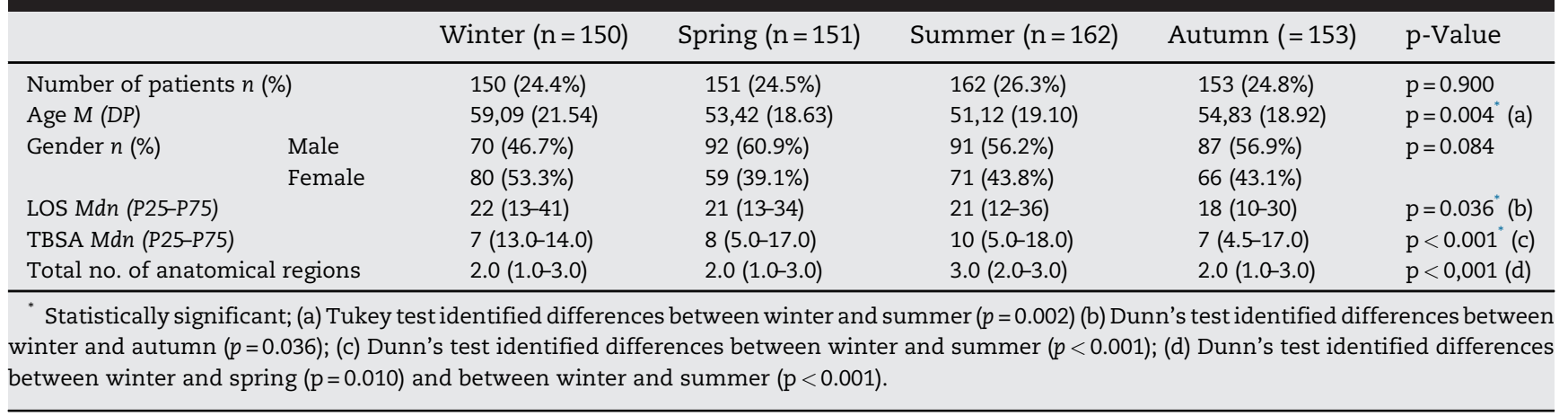


Table 2 - Uni and multivariate Poisson models for LOS.

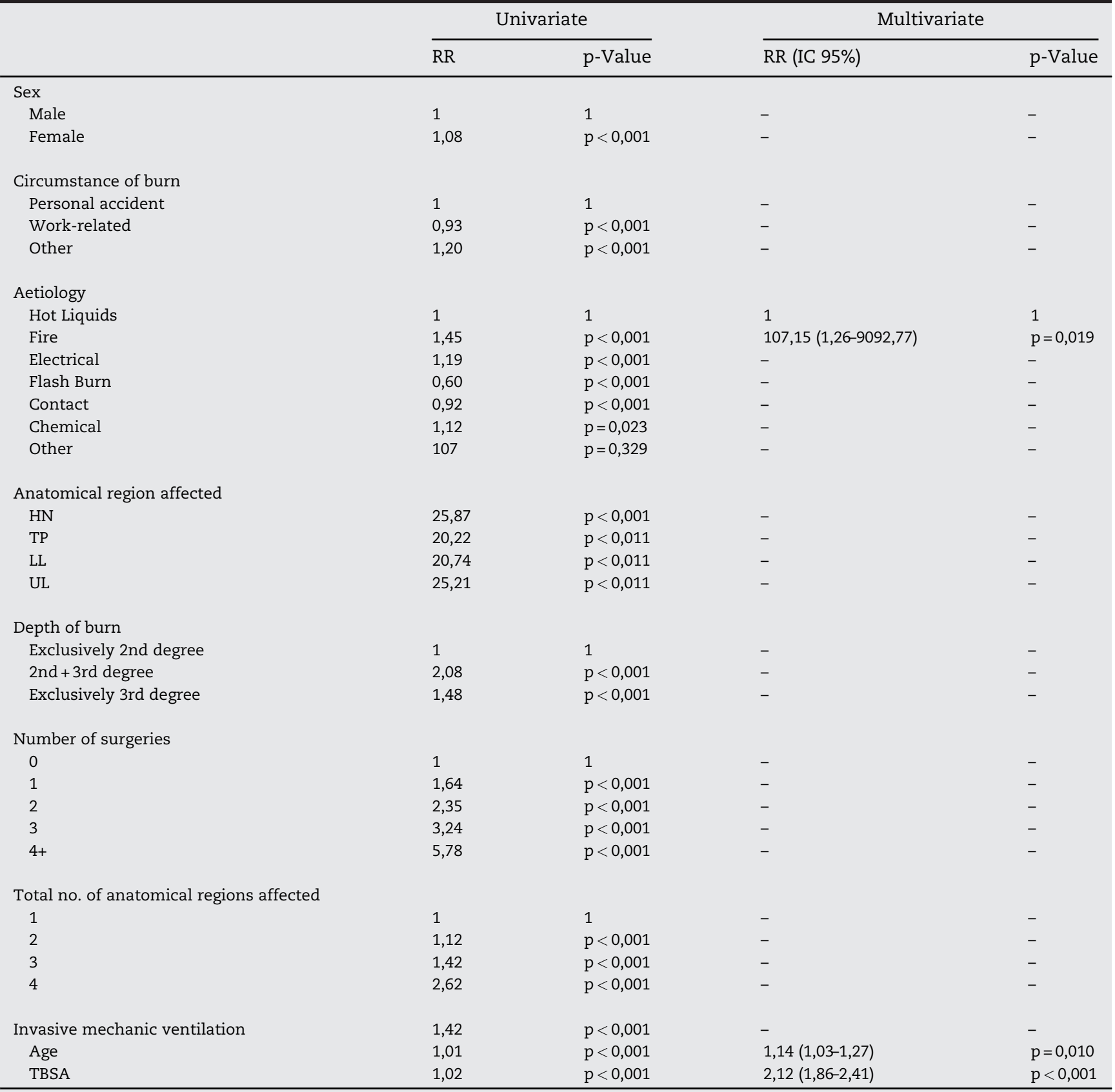

Univariate analysis present only statistically significant variables, that then were included on the multivariate analysis; patients that died during hospital stay were excluded.

differences were found for HN burns $(p=0.026)$, with lower proportion of cases during winter (38\%), for TP burns $(p<0.001)$ with higher proportion of cases in the summer $(66.7 \%)$ and for UL burns $(p<0.001)$ which happened, comparatively, less frequently in the winter (61.3\%) (Table 3). During winter there was a higher frequency of isolated lower limb burns $(n=31$; $20.7 \%)$.

\subsection{Circumstance of burn and aetiology}

From the total 616 patients, 487 (79.1\%) had burns related with personal accidents, 100 (16.2\%) were work-related and $29(4.7 \%)$ were from other causes, namely unknown causes
( $n=12 ; 1.9 \%)$, aggression $(n=9 ; 1.5 \%)$ and suicide attempt $(n=8$; $1.3 \%)$. No significant statistical associations were found between circumstance of burn and season (Table 4). Nonetheless, work related burns were rarer (10.7\%) during winter and much more common during summer (26.4\%).

Regarding aetiology, the most common cause of burn was fire $(49 \%)$, followed by hot liquids (30.8\%), electric and contact burn (5.8\% each), flash burn (4.4\%), chemical $(2.7 \%)$ and less than $1 \%$ for abrasion/friction or unknown causes. The most common cause of burn in all seasons was fire, followed by hot liquids. Flash burn was found to have a higher proportion of cases during spring (6.6\%) and autumn (6.5\%) ( $p=0.044)$. None of the other aetiologies presented significant 
Table 3 - Association of anatomical region affected and depth of burn with season.

\begin{tabular}{|c|c|c|c|c|c|}
\hline & Winter $(n=150)$ & Spring $(\mathrm{n}=151)$ & Summer $(\mathrm{n}=162)$ & Autumn (=153) & p-Value \\
\hline \multicolumn{6}{|l|}{ Anatomical region affected } \\
\hline $\mathrm{HN}$ & 57 (38.0\%) & 81 (53.6\%) & $83(51.2 \%)$ & 79 (51.6\%) & $p=0.026^{*}$ \\
\hline $\mathrm{TP}$ & $67(44.7 \%)$ & $82(54.3 \%)$ & $108(66.7 \%)$ & $80(52.3 \%)$ & $\mathrm{p}<0.001$ \\
\hline LL & $82(54.7 \%)$ & 73 (48.3\%) & 89 (54.9\%) & 74 (48.4\%) & $p=0.465$ \\
\hline UL & 92 (61.3\%) & $117(77.5 \%)$ & $130(80.2 \%)$ & $112(73.2 \%)$ & $\mathrm{p}<0.001$ \\
\hline Depth of burn & & & & & $\mathrm{p}<0,001$ \\
\hline Exclusively 2nd degree & $52(16.2 \%)$ & $84(26.2 \%)$ & $91(28.3 \%)$ & $94(29.3 \%)$ & \\
\hline $2 n d+3 r d$ degree & 70 (29.9\%) & $53(22.6 \%)$ & $60(25.6 \%)$ & $51(21.8 \%)$ & \\
\hline Exclusively 3rd degree & $28(45.9 \%)$ & $14(23.0 \%)$ & $11(18.0 \%)$ & $8(13.1 \%)$ & \\
\hline
\end{tabular}

differences on their distribution considering each season (Table 4). Nevertheless, there was a tendency for contact burns to be more frequent in winter and chemical burns in summer.

\subsection{Depth of burns}

Regarding depth of burn, 321 (52.1\%) of the burns were 2nd degree, divided into superficial 2nd degree burns $(n=80 ; 13 \%)$, deep 2 nd degree burns $(n=27 ; 4.4 \%$ ) and superficial and deep 2nd degree burns ( $n=214 ; 34.7 \%)$. Second and 3rd degree burns accounted for 234 burns (38\%) and finally, there were 61 (9.9\%) exclusively 3rd degree burns (Table 3).

Depth of burn was significantly different between seasons $(p<0.001)$. During winter, there was a lower proportion of exclusively 2 nd degree burns (34.6\%) and a higher proportion of exclusively 3nd degree burns (18.7\%), with combined 2nd and 3rd degree burns being the most prevalent burns (46.7\%).
In the remaining seasons the most prevalent ones were 2 nd degree only burns.

\subsection{Comparisons and associations regarding Circumstance of Burn, Aetiology, TBSA, Anatomical area and Depth of Burn}

A significant association was found for circumstance of burn and aetiology $(p<0.001)$. Both personal and work-related burns were caused mainly by fire and hot liquids. Despite this, electric and flash burn are responsible for a much higher proportion of injuries in the work environment (31\%) as opposed to just $6.2 \%$ regarding personal accidents (Table 5).

When comparing TBSA by circumstance of burn significant differences were found, with higher median of TBSA on workrelated circumstances $(M d n=9.8)$ compared to personal accidents $(\mathrm{Mdn}=7.0)(p=0.027)$. Total number of anatomical regions injured was also higher in work-related circumstances

Table 4 - Association of circumstance of burn and aetiology with season.

\begin{tabular}{|c|c|c|c|c|c|}
\hline & Winter $(\mathrm{n}=150)$ & Spring $(\mathrm{n}=151)$ & Summer $(\mathrm{n}=162)$ & Autumn (=153) & $\mathrm{p}$-Value \\
\hline \multicolumn{6}{|l|}{ Circumstance of burn } \\
\hline Personal accident & $130(86.7 \%)$ & $116(76.8 \%)$ & $121(74.7 \%)$ & $120(78.5 \%)$ & $p=0.835$ \\
\hline Work-related & $16(10.6 \%)$ & $23(15.2 \%)$ & $32(19.8 \%)$ & $29(18.9 \%)$ & $p=0.112$ \\
\hline Other & $4(2.7 \%)$ & $12(7.9 \%)$ & $9(5.5 \%)$ & $4(2.6 \%)$ & $p=0.092$ \\
\hline Suicide attempt ${ }^{\mathrm{a}}$ & $0(0.0 \%)$ & $5(3.3 \%)$ & $3(1.8 \%)$ & $0(0.0 \%)$ & \\
\hline Assault ${ }^{\mathrm{a}}$ & $1(0.7 \%)$ & $4(2,6 \%)$ & $3(1.8 \%)$ & $1(0.6 \%)$ & \\
\hline Unknown $^{a}$ & $3(2 \%)$ & $3(1.9 \%)$ & $3(1.8 \%)$ & $3(1.9 \%)$ & \\
\hline \multicolumn{6}{|l|}{ Aetiology } \\
\hline Fire & $74(49.3 \%)$ & $67(44.4 \%)$ & $84(51.8 \%)$ & $77(50.3 \%)$ & $p=0.578$ \\
\hline Hot Liquids & $46(30.7 \%)$ & 47 (31.1\%) & $50(30.8 \%)$ & 47 (30.7\%) & $p=0.979$ \\
\hline Electrical & $8(5.3 \%)$ & $12(7.9 \%)$ & $10(6.2 \%)$ & $6(3.9 \%)$ & $p=0.528$ \\
\hline Flash Burn & $6(4 \%)$ & $10(6.6 \%)$ & $1(0.6 \%)$ & $10(6.5 \%)$ & $\mathrm{p}=0.044$ \\
\hline Contact & $14(9.3 \%)$ & $9(5.9 \%)$ & $6(3.7 \%)$ & $7(4.6 \%)$ & $p=0.238$ \\
\hline Chemical & $1(0.7 \%)$ & $4(2.6 \%)$ & $8(4.9 \%)$ & $4(2.6 \%)$ & $p=0.121$ \\
\hline Other & $1(0.7 \%)$ & $2(1.3 \%)$ & $3(1.8 \%)$ & $2(1.3 \%)$ & $p=0.801$ \\
\hline Abrasion/ friction ${ }^{a}$ & $1(0.7 \%)$ & $1(0.7 \%)$ & $1(0.6 \%)$ & $0(0.0 \%)$ & \\
\hline Unknown $^{\mathrm{a}}$ & $0(0.0 \%)$ & $1(0.7 \%)$ & $2(1.2 \%)$ & $2(1.3 \%)$ & \\
\hline
\end{tabular}

* Statistically significant.

a Not included for chi-square statistic computation due to low prevalence; Results presented as $n$ (\%). 
Table 5 - Association of circumstance of burn with aetiology.

\begin{tabular}{lccc} 
Aetiology & Personal accident $(\mathrm{n}=487)$ & Work-related $(\mathrm{n}=100)$ & Other $(\mathrm{n}=29)$ \\
\hline Hot liquids & $168(34.5 \%)$ & $20(20 \%)$ & $2(6.9 \%)$ \\
Fire & $241(49.5 \%)$ & $43(43 \%)$ & $18(62 \%)$ \\
Electrical & $20(4.1 \%)$ & $14(14 \%)$ & $2(6.9 \%)$ \\
Flash burn & $10(2.1 \%)$ & $17(17 \%)$ & $0(0.0 \%)$ \\
Contact & $32(6.6 \%)$ & $3(3 \%)$ & $1(3.4 \%)$ \\
Chemical & $12(2.4 \%)$ & $3(3 \%)$ & $2(6.9 \%)$ \\
Other & $4(0.8 \%)$ & $0(0.0 \%)$ & $4(13.8 \%)$ \\
\hline
\end{tabular}

Statistically significant; results presented as $n(\%)$

$(M d n=3.0)$ compared to personal accidents $(M d n=2.0) \quad(p$ $<0.001$ ) (Table 6).

Results showed an association of aetiology with TBSA $(\mathrm{p}<0.001)$. Contact burns $(\mathrm{Mdn}=4.0)$ had lower TBSA when compared with electrical $(M d n=11.0)$ or fire $(M d n=11.0)$. Fire was also considered to have higher TBSA when compared with flash-burn ( $M d n=5.0)$ and hot liquids ( $M d n=7.0)$.

Depth of burn was also significantly different amongst aetiologies $(p<0.001)$. Hot liquids were associated with exclusively 2nd degree burns (70\%), as well as flash burns (92.6\%). On the opposite, contact burns were more associated with exclusively 3rd degree burns (47.2\%). Electric and chemical burns were associated with 2nd and 3rd degree burns $(72.2 \%$ and $41.2 \%$, respectively) (Table 6).

\subsection{Surgical intervention}

From the total 616 patients, 189 (30.7\%) were not submitted to surgery, 200 (32.5\%) had one surgery, 105 (17\%) had two surgeries, $52(8.4 \%)$ had three surgeries and 70 (11.4\%) had four or more surgeries.

The prevalence of patients submitted to surgery was significantly different between seasons $(p=0.006)$ : more patients were operated during winter $(80.7 \%)$ than in the remaining seasons (average 65\%). Regarding the average number of surgeries per season we did not find any significant statistical difference (Table 7).

\subsection{Mechanical ventilation and mortality}

The overall rate of MV was $28.9 \%$ (178 patients). No statistically significant differences were detected across seasons, ranging from $26 \%$ during summer to $36 \%$ during autumn $(p=0.165)$. The overall mortality rate was $6.8 \%$ (42 patients). There were no significant differences in mortality in all seasons. Mortality ranged from $6 \%$ in spring to $7.3 \%$ during winter (Table 7 ).

We found increased risk of invasive mechanic ventilation for work-related accidents opposed to personal accidents $(O R=2.35 ; p=0.016)$, aetiology, considering hot liquids as reference, for fire $(O R=11.16 ; p<0.001)$, electrical $(O R=12.79$; $p<0.001)$, flash burn $(O R=5.65 ; p=0.012)$ and other $(O R=17.58$; $p=0.011)$, anatomical region affected $\mathrm{HN}(\mathrm{OR}=16.84 ; p<0.001)$ and higher TBSA $(O R=1.07 ; p<0.001)$ (Table 8$)$.

We found higher risk of mortality for older patients $(O R=1.03 ; p<0.001)$, higher TBSA $(O R=1.07 ; p<0.001), 2^{\text {nd }}+$ $3^{\text {rd }}$ degree burns $(O R=11.91 ; p<0.001)$ and exclusively $3^{\text {rd }}$ degree burns $(O R=112.54 ; p<0.001)$ and invasive mechanic ventilation $(O R=10.65 ; p<0.001)$ (Table 8).

\section{Discussion}

Burns are one of the most serious traumatic injuries worldwide and they are responsible for approximately 265.000 deaths every year [20]. Even tough the burden of burn injury falls predominantly on the world's poorest populations (over $95 \%$ of fire-related burns occur in low- and middle-income countries) [21] there are still thousands of burn victims each year in high income countries and they represent a significant public health problem $[1,3,19]$.

This paper presents a 7-years data analysis of patients admitted to a specialized Burn Unit in Portugal. There are several epidemiological studies of burns in Portugal, some of

Table 6 - Association of depth of burn with aetiology.

\begin{tabular}{lcll} 
& Exclusively $2^{\text {nd }}$ degree & 2nd $+3^{\text {rd }}$ degree & Exclusively $3^{\text {rd }}$ degree \\
\hline Depth of burn & $133(70,0 \%)$ & $44(23,2 \%)$ & $13(6,8 \%)$ \\
Hot liquids & $143(47,4 \%)$ & $139(46,0 \%)$ & $20(6,6 \%)$ \\
Fire & $4(11,1 \%)$ & $26(72,2 \%)$ & $6(16,7 \%)$ \\
Electrical & $25(92,6 \%)$ & $2(7,4 \%)$ & $0(0,0 \%)$ \\
Flash burn & $6(16,7 \%)$ & $13(36,1 \%)$ & $17(47,2 \%)$ \\
Contact & $6(35,3 \%)$ & $7(41,2 \%)$ & $4(23,5 \%)$ \\
Chemical & $4(50,0 \%)$ & $3(37,5 \%)$ & $1(12,5 \%)$ \\
Other & & & \\
\hline
\end{tabular}

Statistically significant; results presented as $n(\%)$. 
Table 7 - Association of surgery, invasive mechanic ventilation and mortality with season.

\begin{tabular}{|c|c|c|c|c|c|}
\hline & Winter $(n=150)$ & Spring $(n=151)$ & Summer $(n=162)$ & Autumn (=153) & p-Value \\
\hline No. of surgeries & & & & & $p=0.079$ \\
\hline 0 & $29(15.3 \%)$ & $52(27.5 \%)$ & $58(30.7 \%)$ & $50(26.5 \%)$ & \\
\hline 1 & $54(27.0 \%)$ & 49 (24.5\%) & $52(26.0 \%)$ & $45(22.5 \%)$ & \\
\hline 2 & $27(25.7 \%)$ & $22(21.0 \%)$ & $26(24.8 \%)$ & $30(28.6 \%)$ & \\
\hline 3 & $21(40.4 \%)$ & $12(23.1 \%)$ & $8(15.4 \%)$ & $11(21.2 \%)$ & \\
\hline $4+$ & $19(27.1 \%)$ & $16(22.9 \%)$ & $18(25.7 \%)$ & $17(24.3 \%)$ & \\
\hline Invasive mechanic ventilation & $39(21.9 \%)$ & $42(23.6 \%)$ & $42(23.6 \%)$ & 55 (30.9\%) & $p=0.165$ \\
\hline Mortality & $11(26.2 \%)$ & $9(21.4 \%)$ & $11(26.2 \%)$ & $11(26.2 \%)$ & $\mathrm{p}=0.965$ \\
\hline
\end{tabular}

those including only data from Burn Units, but as far as we know none of those as focused primarily in the seasonal variations of burn profiles.

A total of 616 patients were included in the analysis. We did not observe significant differences in patient admissions across seasons. Many studies report an increase in the number of burn patients during winter. Nonetheless most of them come from developing nations $[10,11]$ and others include patients hospitalised but without needing specialized care in a burn unit $[5,17]$. Unsurprisingly the number of injured males was significantly higher compared to females (55\% vs $45 \%$ ) but again no statistically significant gender differences were detected in all seasons. Male predominance in hospitalised burn victims is predominant in the literature ranging from 53 to $72 \%[1,2,19,22]$. They have more high-risk occupations and handle fire and accelerants more often in leisure time activity and household settings [5]. Interestingly, during winter this proportion was reversed, with more women being admitted than men. The use of hot water bags for heating and the increase in indoor cooking during this season, commonly associated with the female gender, might partially explain this difference.

Males were also significantly younger than females (49.1 vs 61.2 years). Bartosch et al. [19] detected a similar difference in the Oporto Burn Unit. Interestingly, patients admitted during winter were older than in the remaining seasons. Older people may be more vulnerable to accidents with fireplaces, gas/ electric heating or seasonal cooking $[5,7,8]$.

The LOS observed in our study was significantly longer for patients admitted during winter. This may be due to the increasing age of the patients, but it can also be attributable to deeper burns since winter was also associated with a higher frequency of third degree burns. Another factor that can explain this result is the higher number of patients operated during this season. It can be expected that operated patients will take a longer time to recovery [11]. The global mean LOS (27.7) across seasons was slightly higher than other comparable studies, ranging from 12.3 to 24.7 days $[9,11,16]$.

The amount of surface area injured was another variable we tested, with summer having the highest TBSA\% of all seasons. Although TBSA varied substantially across patients $(0,5 \%-91 \%)$ the result is unequivocal. We do not believe there is a single reason for this result. In accordance with other publications [2,11] workplace burns and suicide attempts occurred more frequently (although not statistically significant) during this season and they were both associated with higher TBSA\%. The combined number of patients admitted with fire and electric burns was also higher during Summer. We found that these aetiologies of burn were also associated with higher TBSA\%, as demonstrated in other studies $[10,19,22]$. We think it is the combined effect of these circumstances that leads to more extensive burns among patients admitted during summer.

Fire was the dominant aetiology in all seasons, responsible for $44.4 \% 51.9 \%$ of all burns. This result was expected since fire burns are the predominant cause of burns in the adult population, even in industrialized countries. Interestingly, one of the largest burn unit study in Europe in recent years reported a rate of fire related burns even higher of $72.7 \%$ [2]. Some Burn centres have a high rate of infants admitted and they usually report a different main aetiology, with scalds being the most frequent one $[5,10]$.

Although work-related accidents account for a significant portion of patients admitted to the Burn Unit (16.2\%), accidental burns are commonest (79\%). The rate of selfinflicted injury (1.3\%) detected in this study is lower than expected. In the East Mediterranean area self-harm is responsible for $2-37 \%$ of all burn admissions [11] and in Europe the scarce reports available situate the rate of self-inflicted injuries within 3 and $6 \%[19,23]$.

We found a very high proportion of burns affecting multiple anatomic areas (73.9\%) and the most frequently affected area was the upper limb. If the latter result corroborated previous international data regarding burn profiles the former was a surprise. Published studies report rates between $17.6 \%$ and $52 \%$, but most of them include infants with less serious burns $[1,10,18]$. The total number of anatomical regions injured was higher during summer (as expected since summer was also associated with higher TBSA). Interestingly, an isolated lower limb burn was the pattern of burn more frequent during winter as opposed to multiple anatomic areas in the other seasons. We believe this might be attributable to certain specific seasonal extra-risk exposures like the use of hot water bags for heating or seasonal cooking (hot water/tea).

Regarding the depth of burn injury, winter was associated more frequently than any other season with third degree burns. We also found, as in the vast majority of literature, that fire is associated with deeper burns ( $2 n d+3 r d$ and 3rd degree) and hot liquids and flash burns more frequently cause exclusively 2nd degree burns. Winter seems to be associated with lower indoor humidity, an environment conductive to fire ignition and rapid flame propagation, likely to cause more severe fires $[4,24]$. 
Table 8 - Multivariate logistic regressions for invasive mechanic ventilation and mortality.

\begin{tabular}{|c|c|c|c|c|}
\hline \multirow[t]{2}{*}{ Multivariate predictors } & \multicolumn{2}{|c|}{ Invasive mechanic ventilation } & \multicolumn{2}{|c|}{ Mortality } \\
\hline & OR $(95 \%$ CI) & $\mathrm{p}$-Value & OR $(95 \%$ CI $)$ & p-Value \\
\hline Sex & & & - & - \\
\hline Female & 1 & 1 & - & - \\
\hline Male & $1,06(0,60-1,89)$ & $p=0,830$ & - & - \\
\hline Age & $1,01(0,99-1,02)$ & $p=0,300$ & $1,06(1,03-1,10)$ & $\mathrm{p}<0,001^{*}$ \\
\hline Season & - & - & - & - \\
\hline LOS & - & - & - & - \\
\hline \multicolumn{5}{|l|}{ Circumstance of burn } \\
\hline Personal accident & 1 & 1 & 1 & 1 \\
\hline Work-related & $2,35(1,17-4,68)$ & $p=0,016$ & $0,78(0,15-3,97)$ & $p=0,766$ \\
\hline Other & $2,01(0,58-6,91)$ & $p=0,270$ & $0,29(0,03-2,89)$ & $p=0,293$ \\
\hline \multicolumn{5}{|l|}{ Aetiology } \\
\hline Hot liquids & 1 & 1 & & \\
\hline Fire & $11,16(4,09-30,42)$ & $\mathrm{p}<0,001^{\circ}$ & $0,82(0,18-3,75)$ & $p=0,799$ \\
\hline Electrical & $12,79(3,19-51,24)$ & $\mathrm{p}<0,001^{\circ}$ & $0,21(0,01-3,66)$ & $p=0,285$ \\
\hline Flash burn & $5,65(1,45-22,00)$ & $\mathrm{p}=0,012$ & - & - \\
\hline Contact & $1,76(0,26-11,84)$ & $p=0,560$ & $0,63(0,08-5,04)$ & $p=0,664$ \\
\hline Chemical & $3,79(0,68-21,28)$ & $p=0,130$ & $2,19(0,26-18,57)$ & $p=0,471$ \\
\hline Other & $17,58(1,94-159,05)$ & $p=0,011$ & $4,12(0,12-138,28)$ & $p=0,430$ \\
\hline \multicolumn{5}{|l|}{ Anatomical regions affected (a) } \\
\hline HN & $16,84(8,03-35,31)$ & $\mathrm{p}<0,001^{\circ}$ & $0,52(0,13-2,12)$ & $p=0,363$ \\
\hline $\mathrm{TP}$ & $0,69(0,37-1,31)$ & $p=, 262$ & $3,64(0,96-13,87)$ & $p=0,058$ \\
\hline LL & $1,06(0,57-1,97)$ & $\mathrm{p}=, 849$ & $1,60(0,52-4,99)$ & $p=0,415$ \\
\hline UL & $0,88(0,43-1,80)$ & $\mathrm{p}=, 721$ & $0,84(0,21-3,33)$ & $p=0,799$ \\
\hline \multicolumn{5}{|c|}{ Total no. of anatomical regions affected } \\
\hline 0 & 1 & 1 & & \\
\hline 1 & - & - & & \\
\hline 2 & $2,04(0,97-4,27)$ & $\mathrm{p}=, 059$ & $1,41(0,33-6,00)$ & $p=0,642$ \\
\hline 3 & $0,94(0,48-1,87)$ & $\mathrm{p}=, 868$ & $1,71(0,51-5,80)$ & $p=0,387$ \\
\hline TBSA & $1,07(1,04-1,10)$ & $\mathrm{p}<, 001^{*}$ & $107(1,04-1,11)$ & $\mathrm{p}<0,001^{*}$ \\
\hline \multicolumn{5}{|l|}{ Depth of burn } \\
\hline Exclusively 2nd degree & 1 & 1 & & \\
\hline $2 n d+3 r d$ degree & $1,33(0,65-2,70)$ & $p=0,436$ & $11,91(2,67-53,08)$ & $\mathrm{p}<00,001^{*}$ \\
\hline Exclusively 3rd degree & $1,76(0,52-5,95)$ & $\mathrm{p}=, 361$ & $112,54(16,16-783,67)$ & $\mathrm{p}<0,001^{*}$ \\
\hline \multicolumn{5}{|l|}{ Number of surgeries } \\
\hline 0 & 1 & 1 & & \\
\hline 1 & $0,53(0,25-1,15)$ & $\mathrm{p}=, 107$ & $0,10(0,02-0,53)$ & $p=0,006^{*}$ \\
\hline 2 & $0,79(0,34-1,81)$ & $\mathrm{p}=, 571$ & $0,23(0,05-1,14)$ & $p=0,073$ \\
\hline 3 & $1,46(0,51-4,14)$ & $\mathrm{p}=, 482$ & $0,03(0,00-0,27)$ & $\mathrm{p}<0,001^{*}$ \\
\hline $4+$ & $0,68(0,23-2,03)$ & $p=0,492$ & $0,03(0,00-0,19)$ & $\mathrm{p}<0,001^{*}$ \\
\hline Invasive mechanic ventilation & - & - & $10,65(2,75-41,31)$ & $\mathrm{p}=0,001^{*}$ \\
\hline
\end{tabular}

(a) For each anatomical region affected, and invasive mechanic ventilation reference category is "no".

Statistically significant $(p<0,05)$.

Regarding the number of surgical procedures we did not find any significant difference seasonally. We think there is the need in future studies to differentiate treatment categories. Patients successfully treated exclusively with debridement have less severe injuries and better prognosis than those submitted to escharotomies and amputations. This differentiation will be important to completely evaluate if there is any seasonal variation regarding surgical treatment.Regarding the need for MV and mortality rates we did not find any seasonal variability. Our mortality rate (6,8\%) compares favourably against values reported by other Portuguese Burn Units, ranging from 108 to $18 \%[16,17,19]$. The need for MV seems to rise steadily during the last trimester of the year. This may be related to more frequent in-house fires and smoke inhalation and consequently higher rates of inhalation injury.

The multivariate predictors associated with mortality are in accordance with other national and international studies $[11,16,19,22]$. Interestingly, regarding the predictors of $\mathrm{MV}$, work-related accidents and fire/electric/flash burns are associated with increased risk. This highlights the need for better 
prevention strategies in the workplace environment since these injuries can potentially be more harmful.

Taking into account all of the above mentioned we believe there are several changes that need to be implemented concerning the prevention of serious burns in Portugal. Firstly, as this study shows, work-related burns constitute a significant proportion of all admitted burns. The surveillance of the compliance with the safety rules in all work environments (especially those who deal with electrical components, highly inflammable materials or chemicals) is something that needs to be reinforced. Additionally, lawmakers should aggravate the penalties associated with this kind of felony in penal legislation in order to guarantee a severe punishment to companies which do not follow all safety regulation amongst their workers. Secondly, exposure to fire should be vastly reduced and when it occurs it should be in the safest conditions as possible. Several patients were admitted after "barbecue" burns, candle/lamp manipulation and fireplace or slash burning accidents. Mass media and schools, for example, should alert for the risks involved with this kind of activities and inform the population regarding the safety measures everyone should adopt. Lastly, we strongly believe there should be implemented preventive programmes that target the elderly. This population is at the highest risk for burns since they commonly have several predisposing conditions such as living in isolation, low mobility, cognitive impairment and multiple comorbidities. During winter, as this study shows, there seems to be an even higher risk within this population for severe burns. The establishment of telephone reassurance health programs and periodic visits to the households might reduce these injuries.

In our opinion, the strength of this study relies in the broad and detailed analysis of the burn profiles, the significant number of patients included and the period of time it encompasses (7 years).

In spite of this, there are clear limitations. This study is a retrospective analysis of electronic medical data regarding patients admitted to an adult Burn Center. In a few cases complete information was not available (namely aetiology and circumstance of burn). Regarding mechanical ventilation we opted to include all patients submitted to this kind of assisted respiration method since we could not verify the presence of airway injury in all of them. This could be a bias. The results also cannot be extrapolated to infant burns.

This analysis included only patients whose injuries matched the criteria for admittance to a dedicated Burn Centre. More trivial injuries could have a completely different frequency and distribution seasonally.

We also did not evaluate patients' comorbidities. It is not prudent to take definitive conclusions without taking into account the clinical status of each patient prior to the burn episode. More studies need to be designed to evaluate the potential impact of certain pathologies and clinical entities in the burn profile across different seasons. This can be crucial also in the development of preventive measures.

Some of the most seriously injured patients died in the first hours/days of hospitalization. In these cases, although the result was devastating the LOS in the hospital was very short. We opted to include all patients when calculating the LOS of our sample. Nonetheless, if we have excluded those patients from the calculation, the median LOS would very likely be higher and there could be significant differences across seasons.

\section{Conclusions}

In summary, this study suggests that there are several seasonal variations of burn profile. Winter seems to be associated with older patients and with the most severe burns (deeper and needing most often surgery). Work related burns were much more common in the summer as were suicide attempts but with fewer admitted cases. Fire was the dominant aetiology in all seasons.

Fire related burns constitute a real public health problem in Portugal, as proven by last year's deadly forest fires. It is essential to improve our educational campaigns, resource allocation and restrictive legislation in order to eliminate, or at least reduce, this frequently preventable injury.

Burn cases remain significantly high in Portugal and every effort should be exerted on raising awareness of this issue. This study was designed to fill the gap in seasonal burn profile in Portugal and we hope it can help to identify vulnerable patients/time periods and improve prevention strategies in our country.

\section{Contributors}

All four authors made substantial contributions to the following:

(a) The conception and design of the study, acquisition of data, analysis and interpretation of data

(b) Drafting the article and revising it critically for important intellectual content

(c) Final approval of the version to be submitted.

\section{Conflicts of interest and funding}

The authors declare that there are no conflicts of interest.

This research did not receive any specific grant from funding agencies in the public, commercial, or not-for-profit sectors.

\section{Acknowledgements}

We would like to thank the Secretariat of the Plastic and Reconstructive Surgery Division at Hospital S.José, Lisbon, for providing easier access to patient files.

R E F E R E N C E S

[1] Santos JV, Oliveira A, Costa-Pereira A, Amarante J, Freitas A. Burden of burns in Portugal, 2000-2013: a clinical and economic analysis of 26,447 hospitalisations. Burns 2016;42 (4):891-900. 
[2] Schiefer J, Perbix W, Grigutsch D, Zinser M, Demir E, Fuchs P, et al. Etiology, incidence and gender-specific patterns of severe burns in a German Burn Center - insights of 25 years. Burns 2016;42(3):687-96.

[3] Ahn CS, Maitz PK. The true cost of burn. Burns 2012;38:967-74.

[4] Ayoub Aimina, Kosatsky Tom, Smargiassi Audrey, BilodeauBertrand Marianne, Auger Nathalie. Risk of hospitalization for fire-related burns during extreme cold weather. Environ Res 2017;158:393-8.

[5] Müller M, Moser EM, Pfortmueller CA, Olariu R, Lehmann B, Exadaktylos AK. Aetiology of adult burns treated from 2000 to 2012 in a Swiss university hospital. Burns 2012;42(4):919-25.

[6] Harvey L, Connolley AS, Harvey JG. Clothing-related burns in New South Wales, Australia: impact of legislation on a continuing problem. Burns 2015;41:58-64.

[7] Harvey LA, Poulos RG, Sherker S. The impact of recent changes in smoke alarm legislation on residential fire injuries and smoke alarm ownership in New South Wales, Australia. J Burn Care Res 2013;34:168-75.

[8] Clouatre E, Pinto R, Banfield J, Jeschke MG. Incidence of hot tap water scalds after the introduction of regulations in Ontario. J Burn Care Res 2013;34(March-April (2)):243-8.

[9] Hultman CS, Tong WT, Surrusco M, Roden KS, Kiser M, Cairns BA. To everything there is a season: impact of seasonal change on admissions, acuity of injury, length of stay, throughput, and charges at an accredited, regional burn 1 center. Ann Plast Surg 2012;69(1):30-4

[10] Ansari-Lari M, Askarian M. Epidemiology of burns presenting to an emergency department in Shiraz, South Iran. Burns 2003;29(6):579-81, doi:http://dx.doi.org/10.1016/S0305-4179 (03)00066-4.

[11] Othman N, Kendrick D. Epidemiology of burn injuries in the East Mediterranean Region: a systematic review. BMC Public Health 201010(83).

[12] Rohrer-Mirtschink S, Forster N, Giovanoli P, Guggenheim M. Major burn injuries associated with Christmas celebrations: a 41-year experience from Switzerland. Ann Burns Fire Disasters 2015;28:71-5.
[13] Pacheco Compaña FJ, Avellaneda Oviedo EM, González Rodríguez A, González Porto SA. Burn patients during the Summer Solstice festivities: a retrospective analysis in a hospital burn unit from 2005 to 2015. Burns 2016;42(November (7)):1567-72.

[14] Hoang DM, Reid D, Lentz CW. Statewide ban on recreational fires resulted in a significant decrease in campfire-related summer burn center admissions. J Burn Care Res 2013;34(1):74 7.

[15] Santa-Comba A, Amarante J, Malheiro E. Tratamento de queimados. Que perspectivas para a Zona Norte de Portugal? Acta Med Port 1993;6:521-6.

[16] Henriques AM, Gonçalves AI, Matos MM, Amaral MJ. Queimaduras. Estudo retrospectivo da Unidade de Queimados do Hospital de Santa Maria. Acta Med Port 1993;6:527-9.

[17] Ferraro A. Estudo epidemiológico de 1768 doentes queimados. Acta Med Port 1998;11:265-9.

[18] da Silva PN, Amarante J, Costa-Ferreira A, Silva A, Reis J. Burn patients in Portugal: analysis of 14,797 cases during 1993-1999. Burns 2003;29:265-9.

[19] Bartosch I, Bartosch C, Egipto P, Silva A. Factors associated with mortality and length of stay in the Oporto burn unit (20062009). Burns 2013;39(3):477-82.

[20] World Health Organization. Burns - fact sheet n8 365. 2014 Available from: http://www.who.int/mediacentre/factsheets/ fs365/en/. [Cited 26 April 2015].

[21] Mock C, Peck M, Peden M, Krug E, editors. A WHO plan for burn prevention and care. Geneva: World Health Organization; 2008.

[22] den Hollander D, Albert M, Strand A, Hardcastle TC. Epidemiology and referral patterns of burns admitted to the Burns Centre at Inkosi Albert Luthuli Central Hospital, Durban. Burns 2014;40(6):1201-8.

[23] Brusselaers N, Monstrey S, Vogelaers D, Hoste E, Blot S. Severe burn injury in Europe: a systematic review of the incidence, etiology, morbidity, and mortality. Crit Care 2010;14:R188.

[24] Log T. Cold climate fire risk; a case study of the Lærdalsøyri fire, January 2014. Fire Technol 2016;52:1825-43. 